\title{
PROFESSOR JOSÉ PEREIRA LINS: O ACADÊMICO DE DOIS PERFIS ${ }^{\mathrm{i}}$
}

\author{
Luciano Primo da Silva* \\ Paulo Sérgio Nolasco dos Santos**
}

RESUMO: O artigo tem como objetivo principal a abordagem da história de vida do professor José Pereira Lins, cujo nome se tornou emblemático e dos mais representativos para a real compreensão da história e cultura do Estado de MS. Para tanto, procura-se discutir o perfil do homem de letras através de suas atividades como membro representativo em duas Academias de Letras do Estado: a Douradense e a Sulmato-grossense. Por conseguinte, busca-se inserir a análisiie numa reflexão teórico-crítica de natureza comparatista sob a vertente dos estudos de arquivo efontes primárias, com vistas à constituição de um primeiro esboço investigativo em torno da atuação do cidadão e homem de letras que deixou representativo legado histórico e sociocultural.

ABSTRACT: The main objective of the article is to approach the life story of Professor José Pereira Lins, whose name has become emblematic and one of the most representative for the real understanding of the history and culture of the State of MS. To this end, we seek to discuss the profile of the man of letters through his activities as a representative member in two State Academies of Letters: Douradense and Sulmato-grossense. Therefore, we seek to insert the analysis and a theoretical-critical reflection of a comparative nature under the aspect of archival studies and primary sources, with a view to the constitution of a first investigative outline around the performance of the citizen and man of letters that he left representative historical and socio-cultural legacy.

PALAVRAS-CHAVE: José Pereira Lins. Arquivo. Literatura Comparada

KEYWORDS: José Pereira Lins. Archive. Comparative Literature.

\section{INTRODUÇÃO}

Neste artigo procuramos desenvolver uma análise cujo enfoque principal recai sobre o corpus constituído pela trajetória e perfil do intelectual José Pereira Lins, particularmente no que se refere às suas missões junto às Academias Douradense de Letras e Sul-matogrossense de Letras. Nessas associações o professor Lins deixou marcas indeléveis registrando para a história regional e sul-mato-grossense notáveis feitos que o imortalizaram como homem de Letras e cidadão do mundo. Não à toa, seu nome memorável batizou o edifício da Faculdade de Comunicação Artes e Letras da UFGD, em 2004 ${ }^{\text {iii }}$. Para a concretização desse percurso, torna-se fundamental uma verificação de 
bibliografia teórico-crítica compatível com a realização desse trabalho. Por conseguinte, a este aspecto teórico nos voltaremos neste primeiro momento da discussão.

Os estudos acerca da natureza e constituição de arquivos literários têm se tornado um dos objetos mais atrativos e produtivos na contemporaneidade, sobretudo a partir dos estudos de Jacques Derrida (2001) e de Michel Foucault (2013), cujas leituras e reflexões, que servem de embasamento para o presente trabalho ${ }^{\text {iv }}$.

Para o encaminhamento dessa reflexão, chamamos a atenção, inicialmente, para a ampliada discussão sobre arquivos literários, ocorrida por ocasião do "IV Colóquio Internacional A Invenção do Arquivo Literário: Resíduos". (Cf. MARQUES, 2011). Dessas discussões, alguns aspectos ganham relevo: a constituição física e teórica em torno dos arquivos; a localização espacial (instituições do campo público, do âmbito privado, entre outras); as especificidades dos documentos, formação de dossiês, as formas de organização (caixas, entre outros); enfim, as interferências de pesquisadores e profissionais no aspecto organizacional das fontes e acervos.

Desse ponto de vista, Reinaldo Marques, em capítulo intitulado "O que resta nos arquivos literários" (2011, p. 192-203), chama a atenção para a natureza polimorfa e diversificada, variada, que constitui a existência de todo e qualquer arquivo. Inclusive a inevitável contribuição dos estudos comparados e de transdisciplinaridade que se colocam como mediação entre o arquivo e seu entorno e o pesquisador propriamente dito. Ou seja, tratase de tarefa relevante na apuração e elaboração de inventariamentos postos em demanda no trabalho de pesquisa:

\footnotetext{
Com isso, somos confrontados com aquela heterogeneidade própria dos arquivos de escritores, constituídos por acervos arquivísticos, bibliográfico e museológico. Acervos cujo tratamento exige outras modalidades de ações catalogação, restauração, conservação por meio de higienização e acondicionamento adequados, de gerenciamento ambiental, disponibilização para a pesquisa, entre outras - e evidencia a necessidade de um enfoque multidisciplinar na abordagem dos arquivos literários. Para tal enfoque haverão de contribuir, a pardas disciplinas próprias do campo dos estudos literários, alguns saberes especializados, tais como a história, a arquivística, a biblioteconomia, a museologia, a informática, o restauro e a conservação. (MARQUES, 2011, p. 193)
}

A partir daí, o estudioso chama a atenção para o sentido da palavra "resíduos", dos diversos pormenores e objetos que atravessam o universo constitutivo dos acervos de escritores, de indivíduos cujas vidas se tornaram enriquecidas e de relevância para análise cultural: instrumentos como um piano, cachimbos, peças de artesanatos, garrafas de vinho e de cachaça, recortes variados de jornais, pedaços de papeis com anotações (contas, anedotas, nomes e endereços, citações de leituras, diários, medalhas de honra e de mérito), além de objetos pessoais como canetas, mata-borrão... tudo isso demonstrando a 
persistência de uma gama de restos de arquivos rebeldes à classificação, "ao ordenamento, à localização, à guarda por parte de seus arcontes (arquivistas, museólogos, historiadores, pesquisadores)". (Cf. MARQUES, 2011, p. 193-194)

Continua o estudioso destacando o interesse crescente pela custódia e instalação de acervos literários, a exemplo de diversos centros de documentação e pesquisa, que propiciariam distinguir grupos de documentos, a formação de dossiês e a organização em caixas, codificados segundo divisões e subdivisões de fundo. Atividade esta que acarretaria um fator de complexidade ainda maior, na medida em que sujeitos e instituições acabam por re-enquadrar e re-modelar o material de fundo propriamente dito, que resulta, assim, em algo diferente do fundo original, agora disponibilizado ao públicoalvo. Ou seja, examinar como isso tudo afeta a maneira de ler o arquivoconduziria o estudioso pesquisador a uma função especial, a de um anarquivista. (Cf. MARQUES, 2011, p. 199). Como observa o próprio Reinaldo Marques, em palavras mais pontuais:

\begin{abstract}
Dessa maneira, em termos dos referenciais teóricos da pesquisa, sua abordagem deve-se dar a partir de uma metodologia transdisciplinar e comparatista. Comparatista, seja porque um arquivo de escritor costuma ser composto tanto por artefatos verbais - livros, originais manuscritos ou datiloscritos de sua obra, cartas etc. -, quanto icônicos, não verbais - pinturas, esculturas, peças de artesanatos, objetos pessoais -; seja porque cada arquivo, em cada tempo e lugar, privado ou institucional, comporta uma história e uma configuração particulares, irredutíveis a uma história e uma configuração particulares, irredutíveis a uma história totalizante. Assim, o método comparativo, ao contrapor quer diferentes objetos, formas artísticas e discursos, quer distintos modos de arranjo documental, articulando-os de maneira a explicitar suas semelhanças e diferenças, constitui-se numa ferramenta adequada e estimulante para se interrogar e pensar os materiais do arquivo dos escritores. Transdisciplinar, uma vez que, em sua constituição heterogênea, os arquivos literários mobilizam diversos saberes e ofícios, tendo em vista sua localização espacial, catalogação, organização, conservação e disponibilização para o público. (MARQUES, 2011, p. 201)
\end{abstract}

De outro lado, em prolongamento a essas discussões, a estudiosa Tania Carvalhal, no ensaio "Sob a égide do cavaleiro errante" (2006), formula subsídios singulares à função e ao papel das associações de estudiosos, homens de Letras, na constituição e formação de um painel das ideias e das Letras enquanto reflexo da vida e participação dos cidadãos de Letras, homens cultos, que atuando nessas associações constituem um perfil e projeções da vida acadêmica, literária e intelectual no cenário cultural da nação. Assim, a partir da criação das associações de Literatura Comparada, no Brasil e no mundo, Carvalhal põe em relevo a natureza de mediação das associações como a ABRALIC; incluindo-se nessa perspectiva as Academias de Letras, como componente cultural do país. 
Ou seja, as práticas que organizam as instituições literárias cooperam no reconhecimento e legitimidade das práticas culturais e literárias, uma vez que sua natureza mediadora funciona não só como espaço de legitimação, mas também como espaço no qual a literatura se conforma segundo a lógica das mediações. Daí que a existência de associações como as Academias literárias e o papel aglutinador dos escritores nos diversos espaços nacionais e regionais encontram justificativas, inclusive, em campos de estudos tão destacados como a sociologia, por exemplo:

\begin{abstract}
A reflexão sobre a função das associações encontra, então, seus fundamentos menos no campo literário do que nos da antropologia ou da sociologia, porque trata sobretudo de relações sociais que nos levam a indagar sobre o sentido de nossas práticas em tempos e contextos determinados. Dito de outro modo, trata-se de entender que as práticas literárias e culturais têm na esfera social seu lugar específico de exercício e formas particulares de organização. (CARVALHAL, 2006, p. 14)
\end{abstract}

A partir desse ângulo, Carvalhal examina em profundidade a relação ou modo como as associações se articulam favorecendo as aproximações, que, do ponto de vista do comparatismo, inserido no mundo globalizado, faz contrastar os textos e as produções culturais, as personagens, até o ponto de se interrogar sobre o que mudou no mundo e nas relações humanas, tendo em vista a dialética globalização versus localismos. A atenção da estudiosa se deixa entrever nos diversos ensaios que escreveu acerca do assunto, de modo geral enfatizando a importância dos estudos regionais e interculturais e das localidades, das histórias locais, no mundo globalizadov . Desse ponto de vista, são significativas as palavras com as quais Carvalhal não só define a prática dos estudos comparados como também amplia os raios de reflexão e de atividade dos estudiosos no campo das associações e dos estudos comparados. Como se lê:

Entendemos, então, cada vez mais, que não é possível pensar em campos do saber estanques, conclusos e fechados em si mesmos, pois o que se acentua é a natureza híbrida dos diversos domínios do conhecimento e da expressão artística, sua inter-relação [...]. A literatura comparada, como prática crítica, se inscreve no movimento de mudanças das demais modalidades críticas, delas se distinguindo não pelos objetos que estuda, mas pelas perguntas que formula e pelos modos de aproximação de que se vale. (CARVALHAL, 2005, p. 177178)

Tendo em vista essas considerações iniciais, que seguem perspectivas teórico-críticas para a análise do nosso objeto de estudo, nos próximos itens procuraremos analisar o objeto proposto em confluência com a reflexão crítica e com o arquivo do professor José Pereira Lins, anunciado no início desse trabalho.

\title{
1. JOSÉ PEREIRA LINS E A ACADEMIA DOURADENSE DE LETRAS
}


José Pereira Lins, conhecido pelo nome artístico "O Professor", como destacou Heleninha, em Usina Velha: Raios na Chaminé (OLIVEIRA, 2009, p. 101), tomou posse na cadeira de número 7, cujo patrono era Lobivar Matos, no dia 27 de março de 1993. Foi eleito mais tarde vice-presidente (1994/96); presidente por dois mandatos (1996/98), (2002/04) e também 2º secretário (2000/02) da Academia. (Cf. OLIVEIRA, 2009, p. 100103) Em 1996, o professor Lins tomou posse como presidente da Academia, como se vê na imagem a seguir:

Fig. 1: Imagem do novo presidente da Academia Douradense de Letras

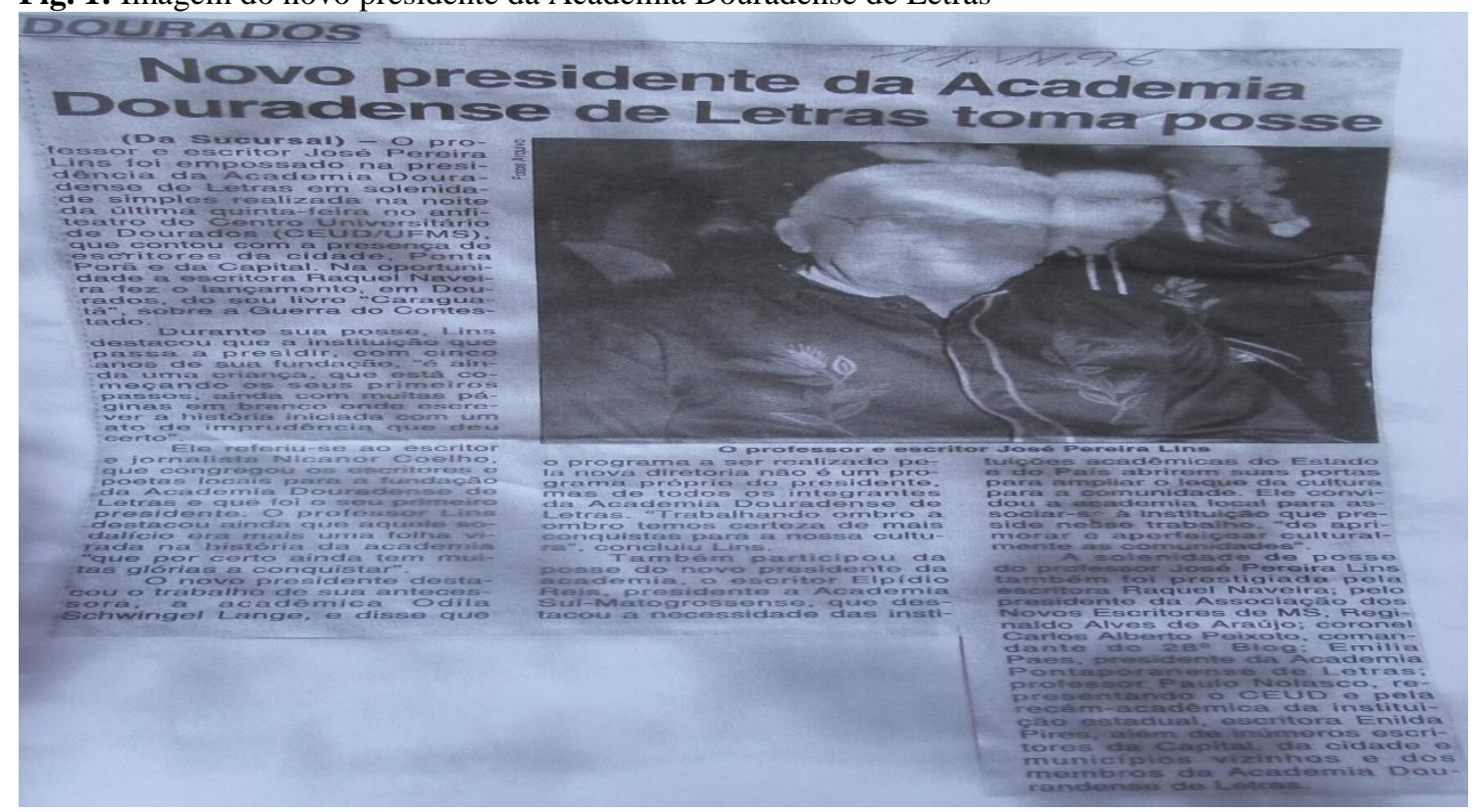

Fonte: Imagem fotográfica em câmera digital, de nossa autoria, extraída do Jornal O Progresso, de 11 nov. 1996, constante em arquivo da ADL/ Dourados. 14 jan. 2016

Nesse sentido, no "Espaço Cultural Casa Arandu" realiza eventos de preservação das culturas existentes com finalidade literária, ações de defesa da língua portuguesa e incentivo à arte. A Academia, então, foi declarada "Utilidade Pública" e noticiada pelo jornal O progresso, que registrou o evento na edição de 19-20de dezembro de 2008, como uma referência cultural:

Fig. 2: A Academia Douradense de Letra é uma referência cultural 

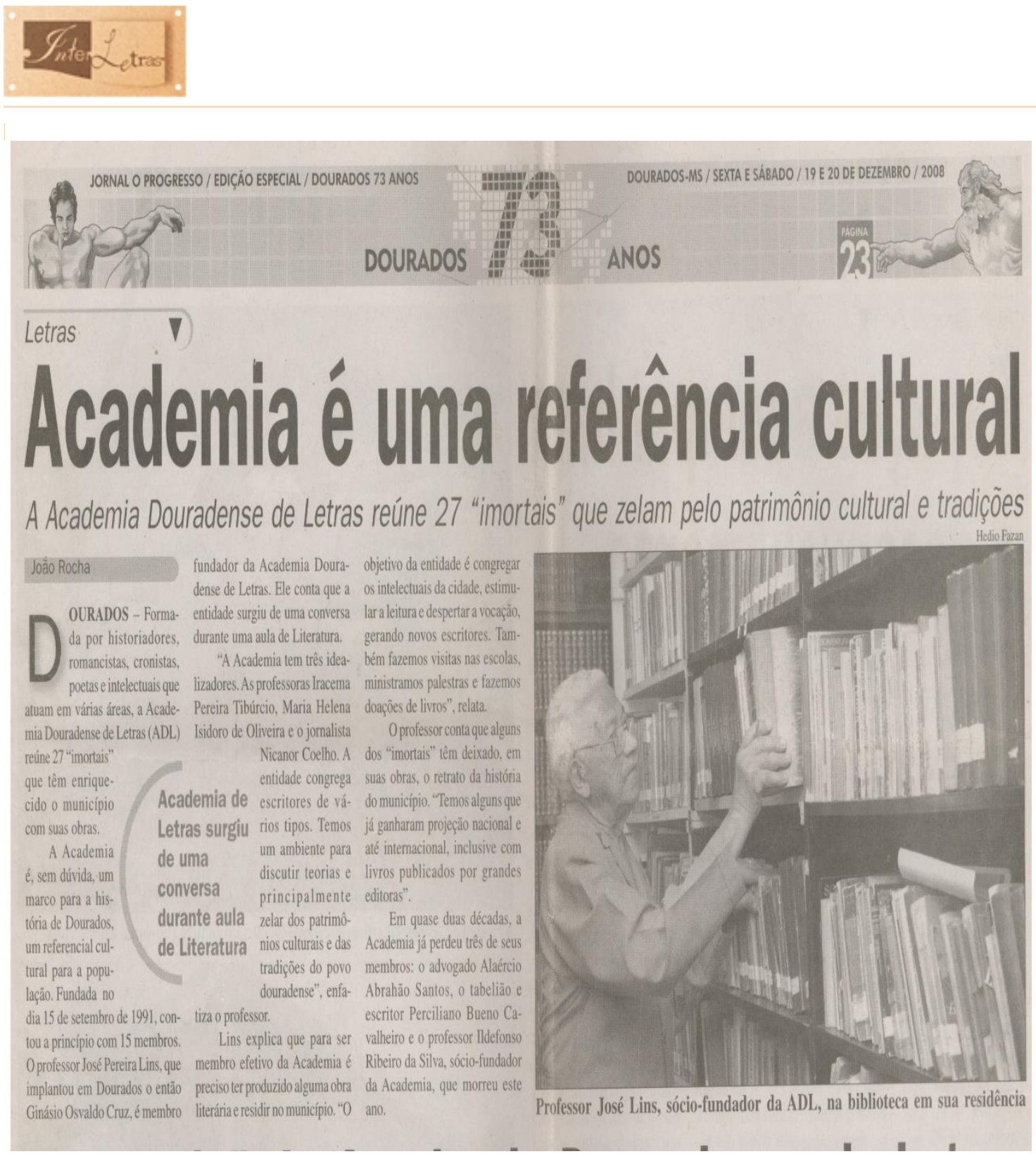

Fonte: Imagem fotográfica em câmera digital, de nossa autoria, extraída do Jornal O Progresso, de 19-20 dez. 2008, constante em arquivo da ADL/ Dourados. 14 jan. 2016.

Considerado homem das Letras, escritor e professor que foi José Pereira Lins, por ter a idade de 72 anos era o mais "idoso" dentre os confrades, no ano de 1993, e, ao se referir à constituição de "famílias literárias", por ser o "orador" dos 15 confrades fundadores, representava um catalisador, e fortalecia, assim, a união familiar dos acadêmicos da Academia Douradense de Letras. E com essa união familiar, o professor Lins, juntamente com os acadêmicos, criou e aprovou um dos meios de divulgação mais importantes da Academia, o jornal Letras Douradenses, tendo o logotipo da entidade nas cores azul, preto, vermelho, branco, verde e a cor grafite ${ }^{\mathrm{vi}}$. 
Vale lembrar, também, o cuidado que o professor Lins teve com as suas "famílias literárias" - obras literárias compostas em sua biblioteca pessoal, que atualmente estão no espaço "Coleção Professor Lins", desde 2009, na Biblioteca Central da UFGD, e que compõe mais de oito mil títulos de obras raras.

É importante ressaltar que, no decorrer dos anos 1996/98, o professor Lins, como presidente da Academia, realizou atividades tanto culturais (concurso de poesias) como de cunho administrativo, efetuando reivindicações para um convênio com a Prefeitura Municipal de Dourados, para dispor de verbas para as realizações dos eventos literários e culturais, como também, serviços de cópias reprográficas. Como a entidade necessitava de recursos como livros, estantes, materiais de limpeza, materiais didáticos, impressoras etc., o presidente Lins, juntamente com os acadêmicos, trabalhou em prol da Academia, realizando participações nos concursos literários a convite do Sindicato dos Bancários, na avaliação e correção de trabalhos literários.

A participação dos acadêmicos também foi preocupação do professor, como modo de divulgar a Academia e envolver os amantes das Letras, incentivando, inclusive, a sua apresentação em aberturas de solenidades, congressos, eventos com recitações de seus poemas, crônicas, prosas poéticas. A sua sucessora na presidência da Academia, Odila Lange, que já tinha exercido a presidência da Academia 1995/96, deu continuidade aos trabalhos propostos pelo professor, como mostramos na imagem a seguir:

Fig. 2: $\mathrm{O}$ professor Lins e a nova presidenta da ADL, Odila Lange.

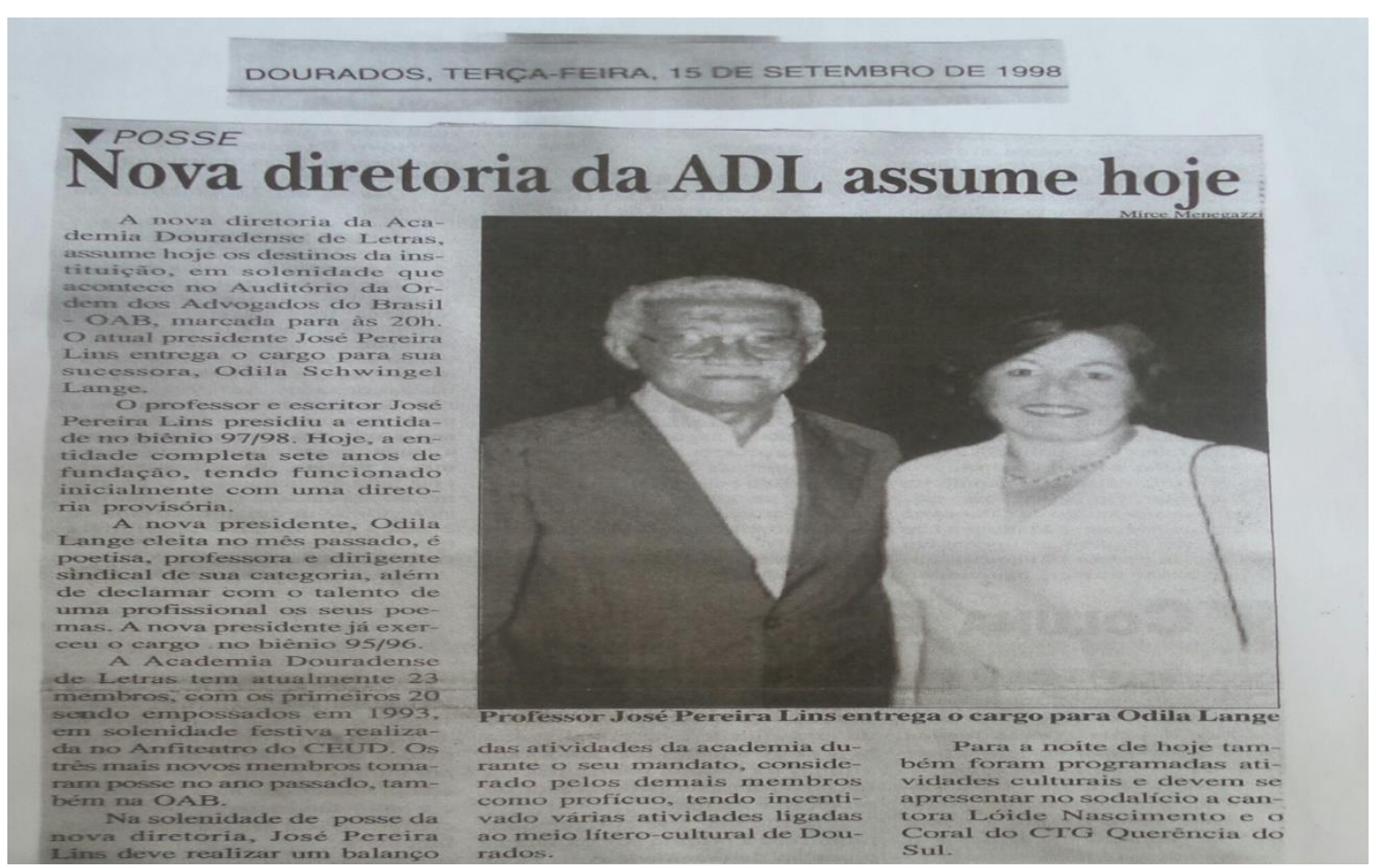


Fonte: Imagem fotográfica em câmera digital, de nossa autoria, extraída do Jornal O Progresso, de 15 set. 1998, constante em arquivo da ADL/ Dourados. 14 jan. 2016

\section{JOSÉ PEREIRA LINS E A ACADEMIA SUL-MATO-GROSSENSE DE LETRAS}

Já na Academia Sul-mato-grossense de Letras, o professor Lins foi empossado no dia 3 de novembro de 1995, na cadeira de número 20, declarada vaga por falecimento do seu ocupante, Otávio Gonçalves Gomes, que tinha por patrono Visconde de Taunay. Sendo assim, eleito em 11 de fevereiro de 1999, completando o mandato de presidente e tendo

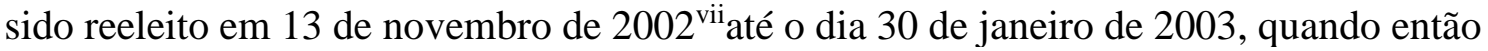
renunciou ao cargo, passou a presidência para o confrade Francisco Leal de Queiroz. Nesse sentido, mostramos a imagem de sua posse na ASL, em cerimônia realizada no anfiteatro do CEUD/UFGD, na cidade de Dourados ${ }^{\text {viii. }}$

Fig. 4: Imagem de posse do professor Lins na Academia Sul-mato-grossense de Letras

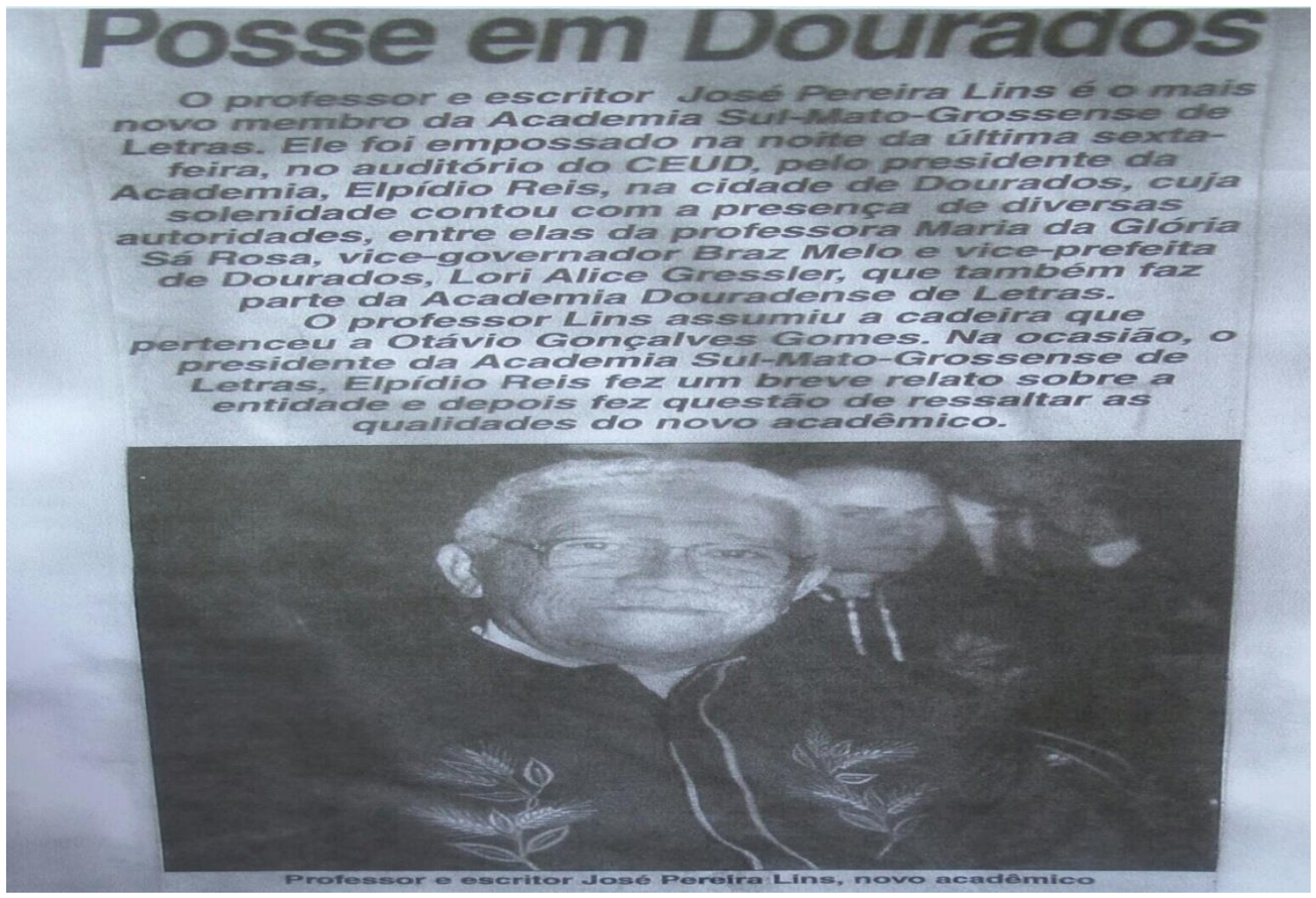

Fonte:Imagem fotográfica em câmera digital, de nossa autoria, extraída do Jornal O Progresso, de 6 nov. 1995, constante em arquivo da ASL/ Campo Grande. 20 nov. 2015 
$\mathrm{Na}$ sede da ASL estava exposta a galeria dos ex-presidentes, onde notamos que o professor Lins figurava ao lado dos demais, ocasião em que fotografamos em câmera digital o mural daquela galeria, de acordo com a imagem abaixo. E não deixaríamos de descrever a importância que teve nessa Associação:

Fig. 5: Imagem do professor José Pereira Lins compondo a galeria dos ex- Presidentes da ASL/Academia Sul-Mato-Grossense de Letras, como presidente no ano de 1999/02 e 2002/03.

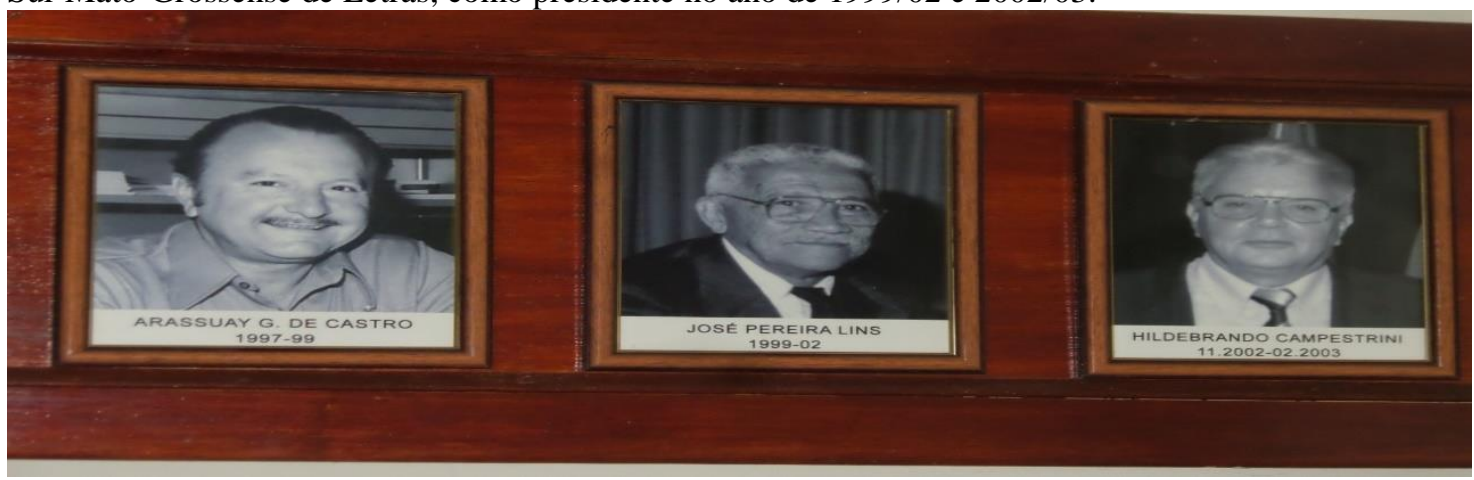

Fonte: Imagem fotográfica em câmera digital, de nossa autoria, extraída diretamente do painel que constitui a galeria de ex-presidentes da ASL/ Campo Grande, em 20 nov. 2015.

O professor Lins, ao realizar os agradecimentos da função de orador da ADL, cita em seu discurso dois nomes da literatura sul-mato-grossense, José Couto Vieira Pontese Maria da Glória Sá Rosa, como principais fundadores da ASL e mantenedores da literatura e da história cultural do Estado de Mato Grosso do Sul. Nisso, ao se referir ao escritor Dr. José Couto Viera Pontes, o professor Lins, em seu discurso da ADL, relatou a importância da Academia Sul-mato-grossense de Letras, que favoreceu a ideia da criação de uma nova entidade em Dourados (1993), conforme se identifica nas palavras do autor José Pontes, em obra História da literatura Sul-mato-grossense (2013):

A instalação da Academia favoreceu, ainda, o interesse pelas artes de um modo geral, nascendo do seu exemplo novas entidades artísticas e culturais em nosso meio; despertou na mocidade o interesse pelas coisas do espírito, e serviu de estímulo ao intercâmbio com entidades congêneres do país, tornando nossa terra, nossa cultura e nossa tradição conhecidas em outras unidades da Federação. ${ }^{\text {ix }}$

A Academia Sul-mato-grossense de Letras no Estado de MS, foi fundada no dia 30 de outubro de 1971 e ficou conhecida pelo nome de Academia de Letras e História de Campo Grande.A sua importância foi reconhecida por Lins, em seu discurso de posse na Academia Sul-mato-grossense de Letras, publicado no jornal Correio do Estado suplemento cultural, de 11-12 de novembro de 1995, em que teceu considerações aos membros fundadores: 
Esta introdução, acentuadamente informal e romântica, está para focalizar a face literária dos ilustres fundadores deste sodalício, já nascido forte e inegavelmente culto. Desde as suas origens, a meio quarto de século. Já convivíamos com eles em quase sua totalidade, mesmo antes que se agregassem como homens e mulheres de letras, sob o sonho de Ulisses Serra. ${ }^{\mathrm{x}}$

Nesse discurso da ASL, o professor Lins volta a atenção em reconhecimento aos antigos confrades, pioneiros, ao Germano Barros de Souza, Ulisses Serra,Luiz Alexandre de Oliveira, Frei Gregório de Protásio Alves, J. Barbosa Rodrigues, Paulo Coelho Machado, Arassuay Gomes de Castro, Otávio Gonçalves Gomes, Maria da Glória Sá Rosa,dentre outros, e em especial, ao escritor José Couto Viera Pontes:

José Couto Viera Pontes inscreve-se na maratona dos que pleiteiam um lugar de destaque entre os modernos contistas do país e vence com garbo e aptidão. Conhece, como nenhum outro a História da Academia e das Letras sul-matogrossenses, além de divulgar a erudição de outros povos. ${ }^{\text {xi }}$

O professor Lins, lembra da relevância de seu confrade antecessor, Otávio Gonçalves Gomes, da cadeira $\mathrm{n}^{\circ} 20$, falecido de uma doença que o aniquilava há anos, e da perda imensa para a entidade, por ele ter sido um dos fundadores, vice-presidente, presidente, secretário geral, membro do conselho Diretor, levando consigo grandes histórias da ASL. Para tanto, o professor Lins finalizou o seu discurso, afirmando que:

O homem vive de seus sonhos, ideais e até ilusões, e certamente, viverá de
"esforço, entusiasmo e até sacrifício" como viveu o acadêmico Otávio
Gonçalves Gomes e certamente eu viverei, pelo seu exemplo, em prol da
Academia. Não são palavras vãs. "Exabundanti a cordis, enim os loquitur".
Mesmo que me falte "engenho e arte", conto com a graça de Deus e com a
vossa benevolência, enquanto sigo passo firme "como toda em pautado
movimento", com os olhos fitos "no Amor, que move o Sol e os outros
Astros"xii

Vale destacar que no ensaio "Parabéns, Academia de Letras!", publicado na Revista da Academia Sul-Mato-Grossense de Letras (2013), José Couto Vieira Pontes chama a atenção acerca da importância da ASL no Mato Grosso do Sul, ao parabenizá-la por seus 42 anos. Vale lembrar que a Academia nasceu a partir do lançamento da obra Camalotes e Guavirais, de Ulisses Serra, no dia 13 de outubro de 1971, que foi o "embrião" da fundação ASL. Dezessete dias após o lançamento de sua obra, ou seja, no dia 30 de outubro de 1971, debaixo de um arvoredo, o escritor Ulisses Serra convidou os cofundadores, Germano Barros de Souza e José Couto Vieira, entre outros amigos, para irem com seu carro "Opala vermelho" até a "Estância Gisele", que ficava na rodovia caminho de São Paulo, a 10 km da cidade de Campo Grande. Nessa "Estância Gisele", os amigos conversavam sobre o "manifesto literário" que se expandia através da corrente dos movimentos dos estudiosos das letras, onde vários escritores da literatura e da história 
cultural de Mato Grosso do Sul dialogavam para fundar um centro cultural em Campo Grande, com o interesse em manter "salvos" os nomes dos escritores, poetas, pintores, etc., que contribuíram na formação da literatura Sul-mato-grossense. Nisso, Ulisses serviu lanche, refrigerantes, e em seguida, subiu em cima de um caixote e disse aos companheiros: "A Academia de Letras e História de Campo Grande está fundada". (Cf. PONTES, 2013, p. 32-33)

Ou seja, os poetas, escritores, artistas plásticos, historiadores, cronistas transformaram a imagem e a ideia daquele momento em obras de artes - escreveram poesia, crônicas e desenharam a cena que presenciavam tão importante naquela data de 30 de outubro de 1971, publicados nas revistas da Academia Sul-mato-grossense de Letras.

Dessa perspectiva, a sessão oficial da ASL aconteceu no dia 13 de outubro de 1972, como afirmou o cofundador José Pontes:

A instalação oficial da entidade deu-se no dia 13 de outubro de 1972, no saguão
do hotel, às 20 horas, presentes altas autoridades e figuras de destaque no
mundo literário, como o escritor e acadêmico Ivan Lins, representando a
Academia Brasileira de Letras; Hernani Donato, Presidente da Academia
Paulista de Letras; Paulo Coelho Machado, representante do Governador José
Fragelli; Hugo Pereira do Vale, da Academia Mato-Grossense de Letras, de
Cuiaba; o General Reynaldo Mello de Almeida, Comandante da $9^{\text {a }}$. Região
militar; General Heitor Luis Gomes de Almeida, Comandante da $4^{\text {a }}$. Divisão
de Cavalaria; o Cel. Agostinho Perlingeiro Perissé, Comandante da Base Aérea
de Campo Grande; Dr. Humberto Canale Neto, Presidente da Câmara
Municipal de Campo Grande; Dr. Ataíde Neri de Freitas, Juiz de Direito,
representando o Poder Judiciário; Assaf Trad, cônsul da República do Líbano;
Armando Silvestrini, cônsul da Itália; Dr. Arnaldo Estêvão de Figueiredo, ex-
Governador de Mato Grosso; Cel. José de Oliveira Lavor, da 9 . Região
Militar; Horácio Lemos, do comércio e pecuária de nosso Estado; Sras.
Constança Corrêa Serra, ao lado dos netos Gisele e Noninho. (PONTES, 2013,
p. 33)

A repercussão nacional da fundação da ASL se deu no decorrer dos anos, com o empenho dos fundadores e confrades em estabelecerem a criação de uma sede própria, que até então se instalava em prédios alugados. Nesse sentido, o confrade Luiz Alexandre de Oliveira, em testamento, doou sua residência, da Rua Rui Barbosa no 2624, no centro de Campo Grande, para a sede da entidade que realizou mudanças a partir do dia 1 de outubro de 1999. (Cf. PONTES, 2013, p. 35)

À época, o presidente da ASL, “o professor” José Pereira Lins escreveu para o jornal Correio do Estado - conforme se registra no caderno B, de 19de fevereiro de 1999, relatando da felicidade de todos com a sede própria: "depois de fazer o trabalho de catalogação, pretendemos realizar os eventos para a comunidade", como obervamos na imagem a seguir: 
Fig. 6:O presidente José Pereira Lins destacando os novosrumos da Academia Sul-mato-—grossense de Letras, com a sede própria.

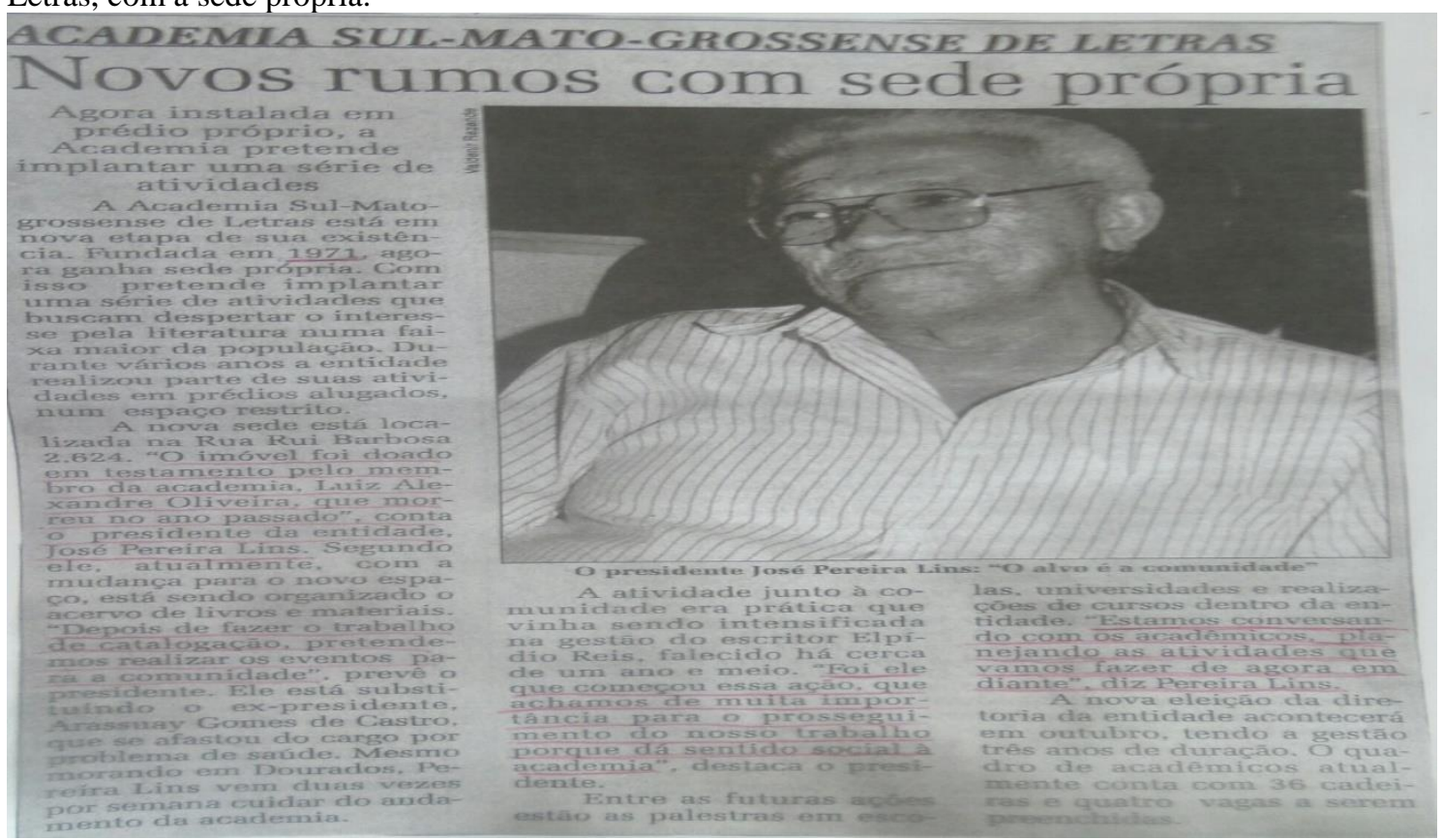

Fonte:Imagem fotográfica em câmera digital, de nossa autoria, extraída do Jornal Correio do Estado, 19 fev. 1999, constante em arquivo da ASL/ Campo Grande. 14 jan. 2016

Na presidência por duas vezes (1999/2002) (2002/2003), o professor Lins permaneceu fiel à ação criada pelo confrade falecido, ex-presidente, o escritor Elpídio Reis: "foi ele que começou essa ação, que achamos de muita importância para o prosseguimento do nosso trabalho porque dá sentido social à academia"xiii. E o professor, então, deu continuidade aos concursos de contos Ulisses Serra, concursos de poesias e manifestações culturais, em campanhas nas escolas, realizando cursos de arte, arte do conto, arte de escrever - com centenas de palestras em todo o Estado e o chá acadêmico, etc., que tinha como alvo "a comunidade", e também, as produções dos acadêmicos, onde foram editadas várias obras no intuito de mostrar a imortalidade e envergadura dos escritores sobre a literatura Sul-mato-grossense.

Nesse sentido, destacamos que o professor Lins se refere especialmente, também, em seu discurso de posse na ASL, à professora Maria da Glória Sá Rosa, que retrata e analisa as interpretações literárias realizadas pelos confrades poetas, escritores, advogados, artistas plásticos, etc., que em sua obra Memória da cultura e da educação em Mato Grosso do Sul: histórias de vida (1990).

Para falar e escrever das coisas sérias, aí está Maria da Glória Sá Rosa. Ninguém hoje poderá envolver-se com as Histórias de Vida na Educação e nas Artes sul-mato-grossenses, sem que, necessariamente, tenha de sentar-se ao lado dessa professora, exímia naquilo a que se tem proposto. ${ }^{\text {iv }}$ 
Em discurso da ADL, o professor Lins se refere à professora Maria Sá Rosa, como exemplo a ser seguido:

\begin{abstract}
A professora Maria da Glória Sá Rosa, da Universidade Federal de Mato Grosso do Sul, sob todos os títulos de inegável e notório saber, no desejo de projetar aqueles que fazem o Brasil de hoje através da Educação, escreveu obra sem similar até o presente, intitulada Memória da cultura e da educação em Mato Grosso do Sul. Neste livro, a educadora procura perpetuar o nome e a memória daqueles que em Dourados puseram em prática os seus sonhos e ideais salientando a significação de seus esforços e contribuição ao progresso dessa região, no setor da educação. É um caminho a ser seguido pela novel Academia. Esta, a missão que lhe é confiada, este o seu dever. Cabe-lhe fazer com que esses ideais perdurem. ${ }^{\mathrm{xv}}$
\end{abstract}

Assim, a referida obra da professora Maria da Glória foi de grande relevância, pois, além de tecer uma imagem do professor Lins e dos outros escritores, advogados, poetas, etc., de que foram pessoas modestas que ultrapassaram dificuldades para se tornarem respeitados na educação do Estado de MS (Cf. ROSA, 1990, p. 174), também serviu como modelo a ser seguido pelo professor Lins, na Academia Douradense de Letras. Ou seja,em exaltação aos confrades, o professor Lins em seus discursos da ADL e ASL, sintetizou a vida acadêmica daqueles que lutaram e fizeram dessas entidades o monumento histórico cultural de Campo Grande e Dourados, e que ainda hoje reúne amigos, escritores, poetas, artistas plásticos, contistas, advogados, dentre outros.

\title{
À GUISA DE CONCLUSÃO
}

Neste artigo, apresentamos alguns dos arquivos inéditos do professor José Pereira Lins, particularmente materiais arquivados na Academia Douradense de Letras e na Academia Sul-mato-grossense de Letras. Frequentemente, os recortes de jornais não têm números de páginas, pois foram armazenadas apenas as notas que se referiam à figura do professor Lins, de modo muito pessoal e particular. Procuramos nos sites dos jornais as matérias inteiras das notícias daquele dia, porém, sem êxito, pois já foram retiradas para acesso público atualmente. Então, exploramos a imagem apenas no que tínhamos em mãos, que se referiam ao professor Lins em seu trabalho como acadêmico e presidente na ADL e ASL, e em seus discursos de posse, onde contribuiu com a criação da nova entidade na cidade de Dourados MS.

Reconhecemos a existência de um amplo e diversificado corpus de estudo envolvendo as academias ADL e ASL, na quais os confrades guardaram um valioso espólio que em nossa pesquisa procuramos registrar e resgatar. E a partir dos quais destacamos os feitos e a imagem de um dos mais importantes nomes das Letras, da cultura e, sem sombra de 
dúvida, um dos maiores trabalhadores na formação cultural e educacional na história de Mato Grosso do Sul, professor Lins.

\section{REFERÊNCIAS:}

CARVALHAL, Tania Franco. Literatura Comparada. Série princípios. São Paulo: Editora Ática, $4^{\circ}$ ed., 2006.

. Encontros na travessia. In: REVISTA BRASILEIRA DE LITERATURA

COMPARADA, $\mathrm{n}^{\circ}$ 7. Porto alegre: ABRALIC, 2005, p. 169-182.

Sob a égide do cavaleiro errante. In: REVISTA BRASILEIRA DE LITERATURA COMPARADA, nº 8. Rio de Janeiro: ABRALIC, 2006, p. 11-17.

DERRIDA, Jacques. Mal de arquivo: uma impressão freudiana. Trad. Claudia de Moraes Rego. Rio de Janeiro: RelumeDumará, 2001, 130p.

FERREIRA, Áurea Rita de A. Lima; MARCHI, Maria das Dores C. Vigário. (org.). 40 anos Letras/FACALE/UFGD: percursos, memórias em tempos e espaços. Dourados-MS: Editora UFGD, 2012.

FOUCAULT, Michel. A Arqueologia do Saber. Rio de Janeiro: tradução Luiz Felipe Baeta, 8 ed., Florence Universitária, 2013.

HELLMAN, Ruth. A história da ADL Academia Douradense de Letras. Dourados: Edição da autora, 2011, 32p.

LINS, José Pereira Lins. O Jardim de Academo. Discurso na Academia Douradense de Letras. 27 mar. 1993, $8 \mathrm{f}$.

LINS, José Pereira. In: ROSA, Maria da Glória Sá. Memória da Cultura e da Educação em Mato Grosso do Sul - História de Vida. Campo Grande: Editora UFMS, 1990, 233p. Capítulo 21: José Pereira Lins, p. 174-178.

LINS, José Pereira. Conceitos. Dourados: Ed. Colégio Oswaldo Cruz, 1995, 67p.

MARQUES, Reinaldo. O que resta nos arquivos literários. In: SOUZA, Eneida Maria de; MIRANDA, Wander Melo. (org.). Crítica e Coleção. Belo Horizonte: editora UFMG, 2011, p. 192-203. 
OLIVEIRA, Maria Elena Izidório de. Usina Velha: Raios na Chaminé. Dourados, MS: $1^{\circ}$ ed., 2009.

PONTES, José Couto Vieira. Parabéns, Academia de Letras!.Revista da Academia Sulmato-grossense de Letras. Campo Grande; MS, n. 24, nov. 2013, p. 32-36.

ROSA, Maria da Glória Sá. Memória da Cultura e da Educação em Mato Grosso do Sul - História de Vida. Campo Grande: Editora UFMS, 1990, 233 p.

\section{MATÉRIAS DE JORNAIS NÃO ASSINADAS:}

ADL abre vaga e realiza eleição. O Progresso. Dourados, MS, 20 ago. 2004.

AQUISIÇÃO do acervo bibliográfico do professor José Pereira Lins. Diário oficial da União. seção 3. Dourados, MS: Fundação Universidade Federal da Grande Dourados, 22 dez. 2009.

A SOLENIDADE da Academia em Dourados. O Progresso. Dourados, MS, 3 nov. 1995. CORES do logotipo da Academia Douradense de Letras e seu simbolismo. Letras Douradenses. Dourados, MS, set. 1995.

DISCURSO de posse na Academia Sul-Mato-Grossense de Letras (ASL). Correio do Estado. Campo Grande, MS, 11, 12 nov. 1995.

LINS assume Academia de Letras de MS. Correio do Estado. Campo Grande, MS, 19 fev. 1999.

NOVO PRESIDENTE da Academia Douradense de Letras toma posse. O progresso. Dourados, MS, 11 nov. 1996.

NOVOS rumos com sede própria. Correio do Estado. Campo Grande, 1999.

RELATÓRIO da investigação acerca das condições do acervo do professor José Pereira Lins. Dourados, MS: Universidade Federal da Grande Dourados, 24 abr. 2009.

'O artigo é resultado da dissertação de mestrado, intitulada "No Arquivo do professor José Pereira Lins: uma leitura entre vida e obra". (Cf. SILVA, 2017, 193 f.)

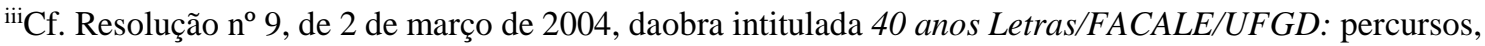
memórias em tempos e espaços, de autoria das professoras Áuria Rita e Maria das Dores, 2012, p. 77.

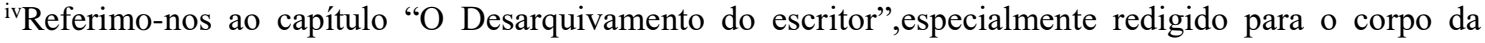
dissertação de Mestrado No arquivo do Professor José Pereira Lins: uma leitura entre autobiografia e obra.

"Ver, nesse sentido, as intervenções de Carvalhal no VIII Congresso ABRALIC, tambémno colóquio "À partir de Venise: Héritages, Passages, Horizons - CinquanteAns de L' AILC", realizado na Universidade Ca' Foscari, nos dias 22-25 set. 2005, bem como no ensaio "Encontros na travessia" (2005), nos quais Carvalhal pontua as relações sociocultuais da Literatura Comparada com a criação de diversas associações dos estudiosos e homens de Letras em âmbito regionais e planetários.

${ }^{v i}$ Cf. O logotipo do jornal Letras Douradense.

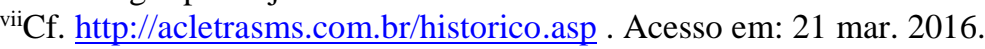


viiiCf. A solenidade da Academia em Dourados.

${ }^{i x}$ Cf. Discurso de posse na Academia Douradense de Letras.

${ }^{x}$ Cf. Discurso de posse na Academia Sul-mato-grossense de Letras.

${ }^{x i}$ Cf. Discurso de posse na Academia Sul-mato-grossense de Letras.

${ }^{x i i}$ Cf. Discurso de posse na Academia Sul-mato-grossense de Letras.

xiiiCf. O jornal Correio do Estado, 19 fev. 1999.

${ }^{\text {xiv }}$ Cf. Discurso de posse na Academia Sul-mato-grossense de Letras.

${ }^{x v}$ Cf.Discurso de posse na Academia Douradense de Letras.

*Mestre pelo Programa de Mestrado em Letras, área de concentração: Literatura e Práticas Culturais.

**Doutorando em Educação área História da educação, Memória e Sociedade - Universidade Federal da Grande Dourados/UFGD - 6799541015 (luciano_primo93@hotmail.com). Professor Dr. Titular de Literatura Comparada na UFGD, (Bolsista produtividade em pesquisa 2 - CNPq). Endereço eletrônico: psergionolasco@gmail.com. 